\title{
Social work and service improvement: An example from the first youth forensic forum
}

\author{
Joanna Appleby, University of Auckland, New Zealand
}

\begin{abstract}
INTRODUCTION: This article focuses on the social work contribution to service improvement by reflecting on the establishment of the first youth forensic forum in Aotearoa New Zealand, held in October 2018.

APPROACH: An exploration of the Aotearoa New Zealand context that led to the establishment of the first youth forensic workforce forum is presented. Issues included disjointed mental health care for young offenders who move between secure residences, concerns about overassessment of vulnerable young people, silo-ed specialist youth forensic knowledge, and a disconnected workforce. Led by a social worker, youth forensic workforce issues were addressed through the inaugural national youth forensic forum in 2018. The aim of the forum was to bring a disparate workforce together in order to improve mental health assessment experiences for young people within youth justice residences. This initiative was grounded in social work approaches of Māori responsivity, networking, ecological systems and relational practice.

CONCLUSION: Social workers have an important role in advocating for, and effecting, system change. The process for doing so within the youth forensic forum is presented. Social workers in all fields of practice are encouraged to consider how they work to make systems more responsive to the people they serve.
\end{abstract}

KEYWORDS: Mental health; youth forensic; systems; policy

AOTEAROA NEW ZEALAND SOCIAL WORK 32(1), 86-91.

CORRESPONDENCE TO: Joanna Appleby joanna.appleby@ auckland.ac.nz
When working as a social worker in a large organisation, it can be challenging to advocate for human rights and social justice, which are core tenets of the social work profession. We can despairingly observe the ways in which bureaucratic service processes are unhelpful for clients, and simultaneously feel ineffectual to create change from within.

Perhaps we underestimate ourselves. As social workers, we are trained to use our sphere of influence to effect positive change. We have the social work tools and knowledge to contribute empowering solutions to systemic issues, even within large-scale organisations.
An example of social work contribution to service change is presented below, with the invitation to consider what changes could be implemented within other fields of practice. The example comes from my work in youth forensics, a fascinating and complex area of practice. The youth forensic landscape is detailed, followed by an exploration of the use of social work values and frameworks to identify a problem, and suggestions on how to implement creative and sustainable solutions.

\section{Youth forensics}

The context for this initiative is the field of youth forensics. Youth forensic services in 
Aotearoa New Zealand have been developed to provide mental health assessments for young people in the youth court, and mental health services for young people in secure Oranga Tamariki youth justice residences (The Werry Centre, 2009). Teams are multidisciplinary, including social workers, and are situated within District Health Boards, with the exception of one kaupapa Māori service with DHB funding (Ministry of Health [MoH], 2011).

Youth forensic services are located within mental health service groups. However, youth forensic work is often practised at the intersection of mental health, youth justice, care and protection, corrections, police, courts, education and disability services. Many young offenders have a history of multiple service involvement, alongside unmet physical, social and emotional needs (The Werry Centre, 2009). Interagency collaboration is a foundation for effective youth forensic practice.

Ten years ago, the $\mathrm{MoH}$ (2010) identified a lack of youth forensic services in Aotearoa New Zealand as an issue of national significance, and work was undertaken to strengthen the sector. A guidance document about youth forensic service development was published, and a number of workforce recommendations were made (MoH, 2011). In regard to workforce skills, it was recommended that youth forensic clinicians be competent in a wide range of areas, including assessment and response to mental health and drug and alcohol issues, developmental issues, intellectual disability, youth justice legislation, youth and family engagement, cultural competency, and cross-sector collaboration $(\mathrm{MoH}, 2011)$.

Since that time, there has been significant investment into youth forensics, with increased workforce numbers, the establishment of a youth forensic inpatient unit, and funded postgraduate study options in youth forensic psychiatry. However, there remain several issues for this field of practice.
There are pertinent social issues related to youth forensic work. There is welldocumented racial bias within the criminal justice system that results in unacceptably high numbers of young Māori being placed in secure care (Maxwell, Robertson, Kingi, Morris, \& Cunningham, 2004; Morrison, 2009; Snelgar, 2019). The US concept of a school-to-prison pipeline can be applied in Aotearoa New Zealand, with particular discrimination against indigenous youth, those who are disabled, and sexually diverse (McCarter, 2017). Invariably, those young people seen in youth forensic services have had a challenging history with education services, and there is growing acknowledgement of the prevalence of neurodisability among young offenders (Lynch, 2016). The concept of incarceration as a crime deterrent has been questioned, and there are several organisations focused on criminal justice reform, including 'Just Speak' and 'People Against Prisons Aotearoa'. Just recently, the 'Safe and Effective Justice Advisory Group' released a report detailing the failure of our criminal justice system, and advising whole system transformation (Te Uepū Hāpai i te Ora, 2019).

Youth forensic teams provide mental health services for young people within youth justice residences. There are four youth justice residences in Aotearoa New Zealand, located in Auckland, Rotorua, Palmerston North and Christchurch. While a young person can be sentenced through the youth court to be placed in a residence for up to six months, a recent review by the Office of the Children's Commissioner (2019) found that $80 \%$ of the 140 young people in youth justice residences were on remand while awaiting a court outcome. This means that often the charges against them have not yet been proved. Those young people on remand will remain in residence for an indeterminate period as their case progresses through the legal system.

Additionally, at least 70\% of the young people in residence are Māori (Office of 
the Children's Commissioner, 2019). While the ideal is to keep young people close to whānau, and in the residence closest to home, the reality is that young people can be placed in any of the residences, and there is often movement of young people between the residences. It is not uncommon for a young person to have been in more than one residence, and some have experienced all four.

There are tensions for social workers in this field, working within justice and social systems that most of us identify as somewhere on the continuum between variable and harmful to young people. The challenge for social workers is to identify the areas where we do have influence, and to take the opportunities to exert our influence and effect positive change.

\section{Locating the problem}

Alongside the societal issues discussed above, there is also the specific issue of overassessment of young offenders due to youth forensic workforce fragmentation (Appleby, Shepherd, \& Staniforth, 2019). While youth forensic clinicians are skilled at collaborating with other local agencies, there has been a lack of collaboration between the various youth forensic teams around the country. This has impacted upon the mental health service that young people receive in youth justice residences, particularly due to the high levels of movement between residences, with some young people being assessed by several youth forensic teams (Appleby et al., 2019).

Each of the four residences has a youth forensic team who provide mental health assessments for young people, usually upon admission to the residence. Despite assessing the same young people, the four youth forensic teams had very little contact between them prior to 2018. There is no shared database of information, and so young people could be involved in multiple mental health assessments, unbeknownst to the assessor. A major contributing factor has been the absence of a national mental health database, as each District Health Board has their own database system. This is a major concern, for reasons pertaining to a young person's experience of assessment and potential risk of poor engagement, but also to issues of risk and safety. Assuming an acceptance of this glaring technological deficit, my focus turned to my potential areas of influence in order to improve the experience of assessment for young offenders.

During my work as a youth forensic social worker, I was involved in a research project about youth justice residences. As part of the project, I was able to meet with all four youth forensic teams, and established ongoing working relationships. It was recognised that those relationships were developed out of face-to-face interactions, whakawhānaungatanga and building trust through the research process. A plan was then made to use those existing relationships to build a network across the whole youth forensic workforce - in order to enhance assessment information-sharing and, hopefully, improve the experience of young people in the residences through a unified and connected workforce. Social workers have a range of tools that are useful when contemplating system change and service reform. In this example, kaupapa Māori approaches, along with networking and using existing resources, were the means for change.

\section{Initiating a solution}

After locating part of the problem in a disconnected workforce, the goal was to bring the youth forensic workforce together, to build a professional community, and start the conversation about how best to respond to assessment needs in residences.

The first ever national youth forensic forum was held in October 2018. It was attended by all of the youth forensic teams around the country. It was marae-based, and deeply embedded in kaupapa Māori process. 
The theme of the forum was kanohi-kite-kanohi (face-to-face), to highlight the relational aspect of the kaupapa. The forum began with a pōwhiri, where the kaumatua encouraged youth forensic clinicians to incorporate culture and spirituality within holistic assessments. Following the pōwhiri, there was a hāngi dinner, prepared and cooked by members of the local youth forensic team. The evening was spent in whakawhānaungatanga, getting to know clinicians in personal and professional spheres. Attendees were invited to stay the night on the marae, sleeping next to each other in the wharenui. Breakfast was provided by the hosting team, before the first speaker of the day.

The keynote address was delivered by Julia Whaipooti, a member of the 'Safe and Effective Justice Advisory Group', chair of 'Just Speak', and senior advisor to the Office of the Children's Commissioner. She skilfully challenged the group to seriously consider what can be done for Māori young people in the system. Dr Ian Lambie, Chief Science Advisor for the justice sector, encouraged attendees to consider the political aspect of the work, and ways that clinicians can contribute to policy change. Each region had an opportunity to share some of their local knowledge. A selection of the presentations can be found online at https://werryworkforce. org/professionals/training-and-events/youthforensic-forum 2018.

This was the first time that the youth forensic workforce had come together at a national level, and was the start of cross-DHB relationships within this field of practice. Forum evaluations by the attending clinicians were overwhelmingly positive, particularly regarding the Māoritanga processes. Clinicians committed to continuing the forum on an annual basis, hosted by the various regions. Working relationships were established across teams, resulting in a greater flow of health information shared between teams, particularly for those young people who moved between residences, and who had significant mental health needs. The goal of bringing the workforce together and building relationships had been achieved, and the second youth forensic forum was held in Porirua in November 2019.

\section{Social work approach to system change}

There were several key factors that led to the forum's establishment. These include Māori cultural guidance, partnering with existing resources, and having confidence in social work contributions. These social work approaches, which we use on a daily basis, were applied to effect system change.

One of the first steps in the process was to partner with a senior Māori cultural advisor. Given the overwhelming majority of youth forensic work is with Māori rangatahi, and we have an explicit social work and mental health commitment to the Treaty of Waitangi, this was a crucial first step. Patrick Mendes provided invaluable cultural wisdom. It was his idea to turn the event into a noho marae, in order to move beyond strict professional boundaries, to engage in true whakawhānaungatanga. He challenged the group to move beyond theoretical discussions of Māori responsiveness, and to engage in experiential learning about Māoritanga. He worked tirelessly, organising the marae stay, preparing the ground for hāngi, and networking with other cultural advisors. Social workers are committed to bicultural practice. As a Pākehā social worker myself, it was important to ensure that Māori perspectives were prioritised before, during and after the event.

The second factor in the forum's success came from the social work skill of networking and using existing resources. Early on, I partnered with Werry Workforce, Whāraurau. They are funded by the Ministry of Health to deliver a number of workforce development initiatives for the infant, child and adolescent mental health and alcohol and other drugs sectors. The Werry team ensured the smooth running of 
the forum through their expertise in event management. Relationships formed during the earlier research process were leveraged to encourage forum participation from all youth forensic teams.

The third factor in the establishment of the forum was my commitment to social work values, and the confidence to stick to these within a hierarchical mental health system. Social workers have the opportunity to challenge the dominant medical paradigm, and to lead initiatives that make services more responsive to the people they serve. In youth forensic services there can be an emphasis on specialist subject knowledge and expertise. While acknowledging the need for expertise, it can also be challenging for social workers working within recovery frameworks, viewing the young person as an expert in their own life. Within competing frameworks, there were tensions in the planning stage between focusing primarily on the forum's content versus process; focusing on specialist expert knowledge dissemination versus building relationships. While agreeing that youth forensic specific learning was important, I was convinced that, for any learning to be meaningful and long term, there needed to be a solid foundation of relationship and connection within the workforce, and that this could lead to improved outcomes for young people. This was based in the research findings about the importance of relationship as a prerequisite for effective informationsharing (Appleby et al., 2019) as well as Māori concepts of whakawhānaungatanga, and ecological systems theory (Bronfenbrenner, 1979).

Finally, establishing this forum was not dependent on any formal leadership position. It simply involved a social worker identifying a service gap, putting forward a proposal, and securing partnerships to help this happen. In mental health, as well as other fields of practice, service improvements can often be seen as only able to be initiated from the level of service leader. This need not be the case. As social workers, wherever we are within a service hierarchy, we can use our critical thinking skills, understanding of systems, commitment to anti-discriminatory practice, and attunement to client needs, in order to shape service reform.

\section{Laying down the wero}

Social workers who think critically about systems are well placed to consider how services can work better. Advocating for service change is our core business, and is a real strength of the social work lens within multi-disciplinary teams. Every day we work with people to discover solutions, often in the face of great adversity. These are transferable skills and can, and should, be applied to the organisation we work in.

There is scope for further improvement in lots of youth forensic areas, including working closely with Oranga Tamariki around managing transitions between residences in ways that limit disruptions to therapeutic interventions. The youth forensic forum was just one example of service improvement in a specific context. I hope that this example will encourage other social workers to think about how they can implement improvements in their own services.

There are many opportunities for social workers to effect organisational change in their field of practice. Social workers recently submitted feedback on mental health service transformation, contributing to the Government Inquiry into Mental Health and Addiction (2018). There are several local initiatives in mental health services, partnering and collaborating between community agencies. For social workers in other fields, there will also be practice wisdom and ideas about how services can be more mana-enhancing. Many social workers are quietly influencing services to be flexible in referral criteria, working hard to soften the rigidity of silo-ed agencies. We work within the context of chronically under-resourced social services often competing against 
each other for precious funds. Despite these adversities, we continue to practise systemic and strengths-based approaches, looking for ways to work together.

Social workers are great at finding creative solutions. We have a responsibility to share our wisdom, and ensure that there is a social work voice included in service improvement. Social workers are equipped with the theoretical and practical knowledge that is needed to keep services accountable and responsive to the people we serve.

Accepted: 28 February 2020

Published: 14 April 2020

\section{References}

Appleby, J., Shepherd, D. M., \& Staniforth, D. B. (2019). Speaking the same language: Navigating informationsharing in the youth justice sphere. Aotearoa New Zealand Social Work, 31(1), 59-71. doi:10.11157/ anzswj-vol31iss1id537

Bronfenbrenner, U. (1979). The ecology of human development: Experiments by design and nature. Cambridge, MA: Harvard University Press.

Government Inquiry into Mental Health and Addiction. (2018). He Ara Oranga: Report of the Government Inquiry into Mental Health and Addiction. Retrieved from www. mentalhealth.inquiry.govt.nz/inquiry-report/

Lynch, N. (2016). Neurodisability in the youth justice system in New Zealand: How vulnerability intersects with justice. Retrieved from https://papers.ssrn.com/sol3/papers. cfm?abstract_id=2869502

Maxwell, G., Robertson, J., Kingi, V., Morris, A. \& Cunningham, C. (2004). Achieving effective outcomes in youth justice: An overview of findings. Wellington, New Zealand: Ministry of Social Development.

McCarter, S. (2017). The school-to-prison pipeline: A primer for social workers. Social Work, 62(1), 53-61. doi:https:// doi.org/10.1093/sw/sww078

Ministry of Health. (2010). Review of forensic mental health services: Future directions. Wellington, New Zealand: Author.

Ministry of Health. (2011). Youth forensic services development: Guidance for the health and disability sector on the development of specialist forensic mental health, alcohol and other drug, and intellectual disability services for young people involved in New Zealand's justice system. Wellington, New Zealand: Author.

Morrison, B. (2009). Identifying and responding to bias in the criminal justice system: A review of international and New Zealand research. Wellington, New Zealand: Ministry of Justice.

Office of the Children's Commissioner. (2019). Supporting young people on remand to live successfully in the community. Retrieved from https://www.occ.org.nz/ assets/Uploads/ShortReport-May2019-Pages2.pdf.

Snelgar, K. (2019). Decolonising the justice system. Retrieved from https://www.rnz.co.nz/national/ programmes/saturday/audio/2018710206/decolonisingthe-justice-system.

Te Uepū Hāpai i te Ora. (2019). He waka roimata: Transforming our criminal justice system. Retrieved from https://safeandeffectivejustice.govt.nz/assets/ Uploads/fa55462d44/teuepureport_hewakaroimata.pdf

The Werry Centre. (2009). A literature review: Mental health and alcohol and other drug screening, assessment and treatment for youth justice populations. Retrieved from http://www.werryworkforce.org/professionals/ publications-and-resources?tid=All\&tid_1=All\&tid_2=All\& field_released_date_value[value]\&page $=2$ 